\title{
Stochastic scheduling and control using data-driven nonlinear dynamic models: application to demand response operation of a chlor-alkali plant
}

\author{
Jodie M. Simkoff ${ }^{1}$ and Michael Baldea ${ }^{* 1}$
}

${ }^{1}$ McKetta Department of Chemical Engineering, The University of Texas at Austin 200 East Dean Keeton Street, Stop C0400, Austin, Texas 78712, United States

April 21, 2020

${ }^{*}$ Corresponding author. Email: mbaldea@che.utexas.edu 
FMM bids: $\Sigma_{1}$

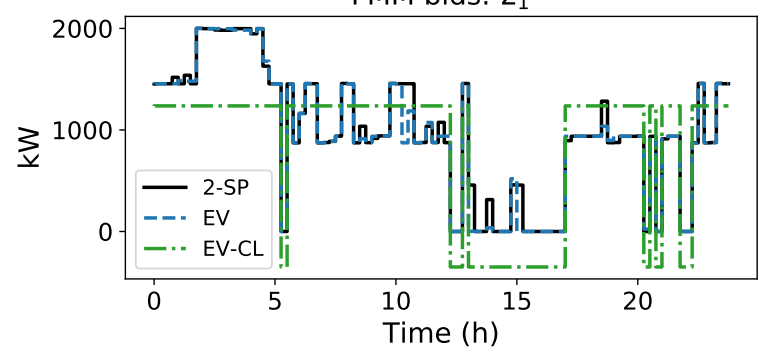

FMM bids: $\Sigma_{2}$

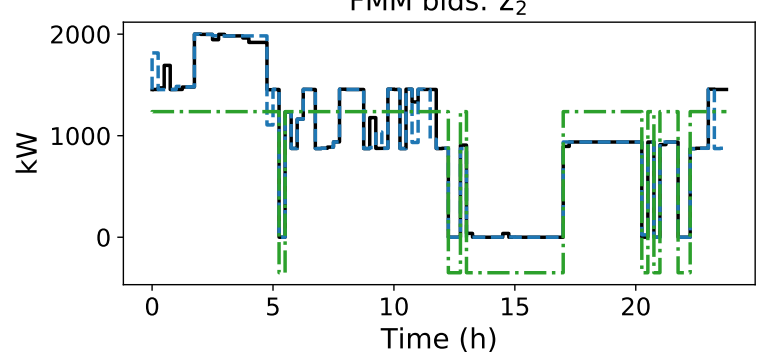

FMM bids: $\Sigma_{3}$

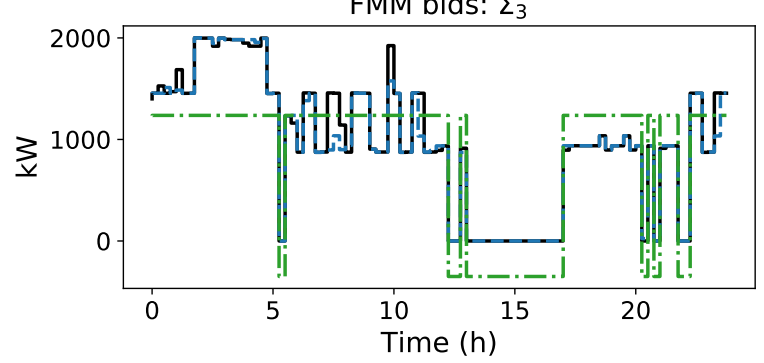

FMM bids: $\Sigma_{4}$

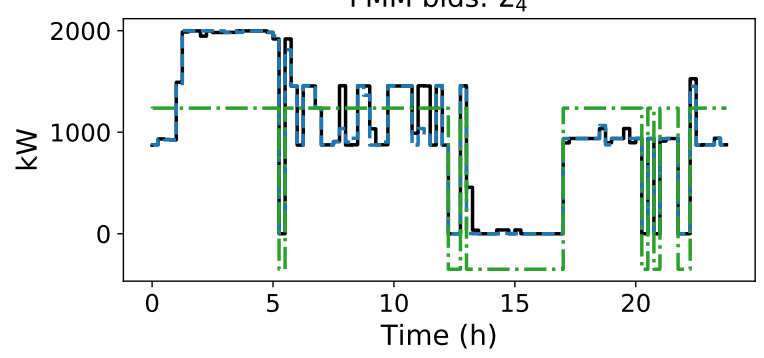

FMM bids: $\Sigma_{5}$

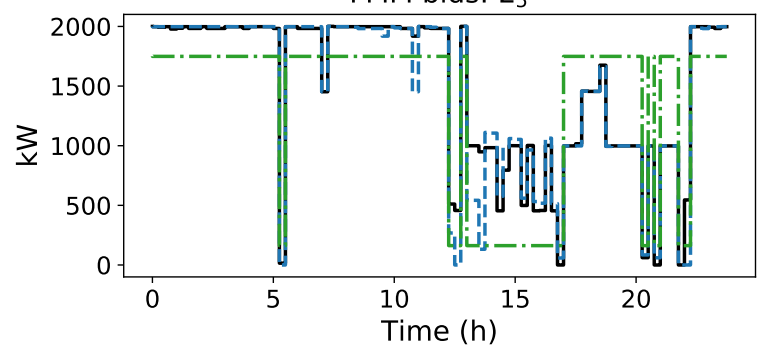

FMM bids: $\Sigma_{6}$

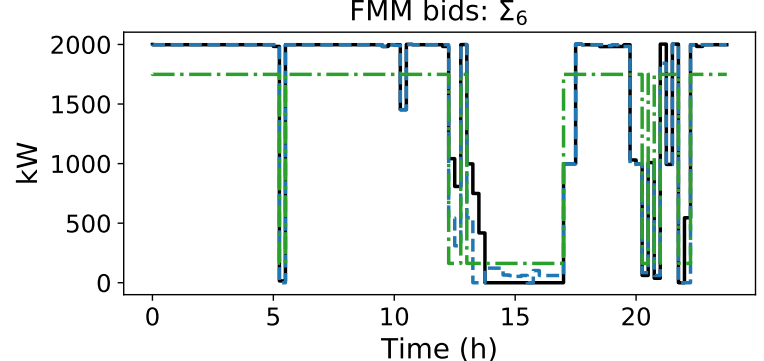

FMM bids: $\Sigma_{7}$

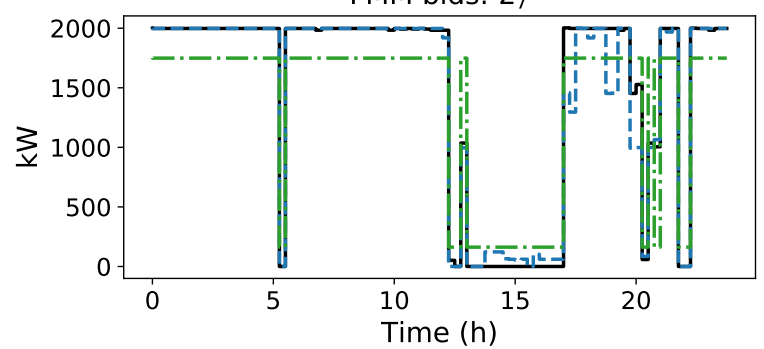

FMM bids: $\Sigma_{8}$

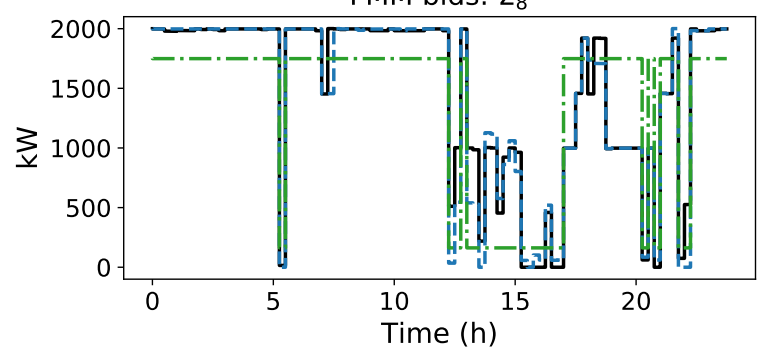

Figure S1: Stochastic programming case study results: FMM bids per scenario (left column: low demand scenarios, right column: high demand scenarios) 

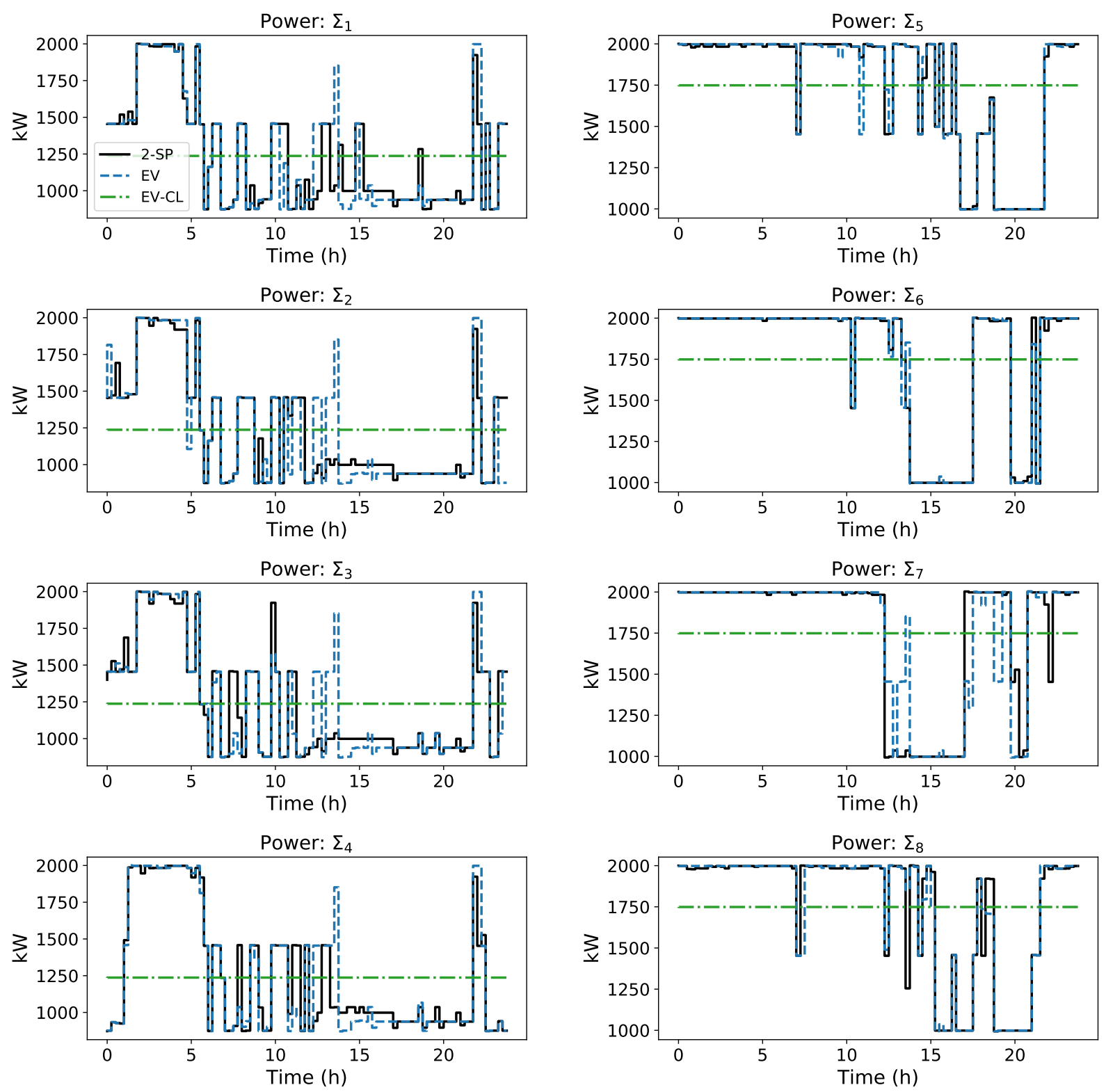

Figure S2: Stochastic programming case study results: total power bids $=$ FMM + DAM, per scenario (left column: low demand scenarios, right column: high demand scenarios) 

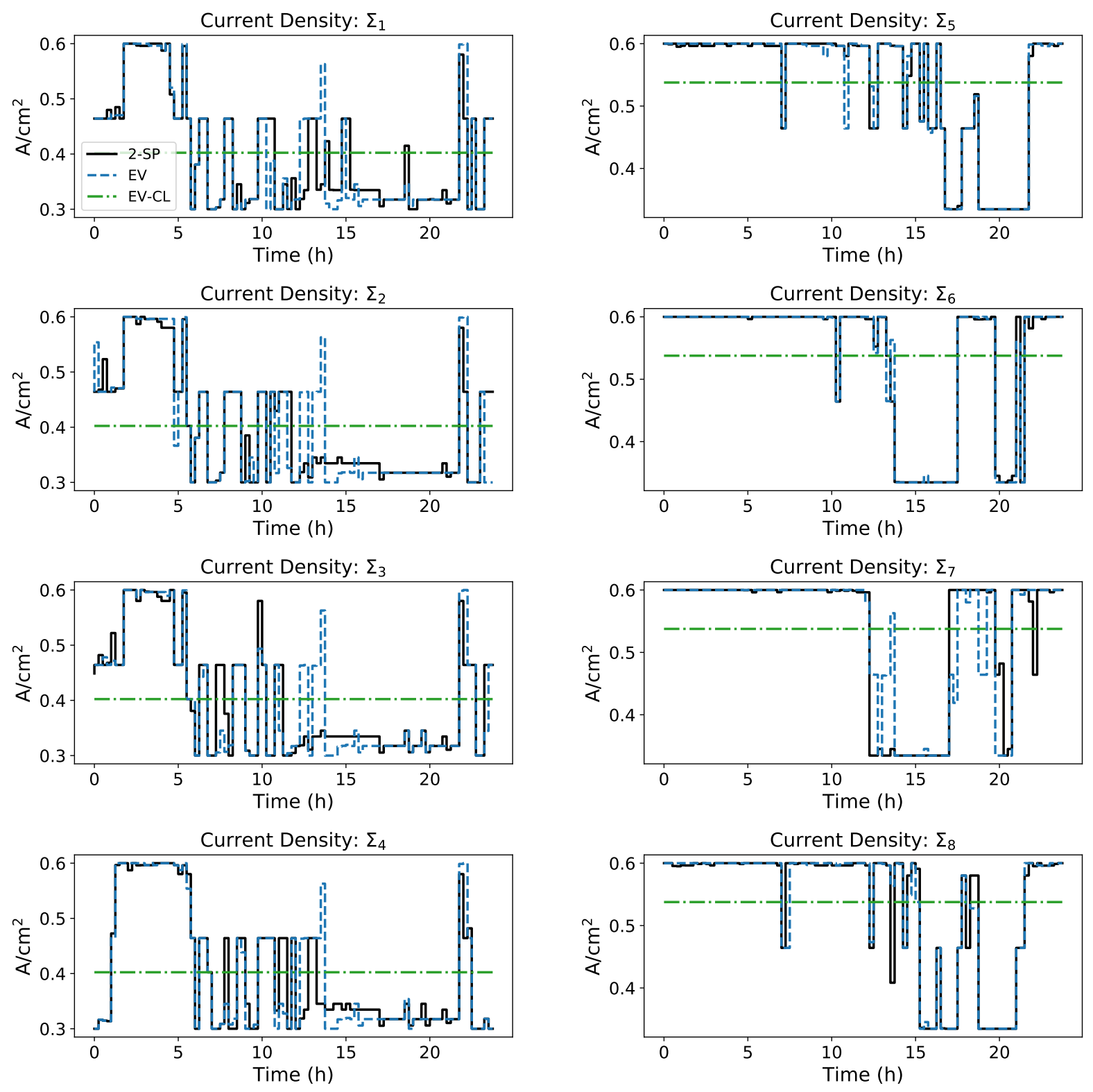

Figure S3: Stochastic programming case study results: current density per scenario (left column: low demand scenarios, right column: high demand scenarios) 

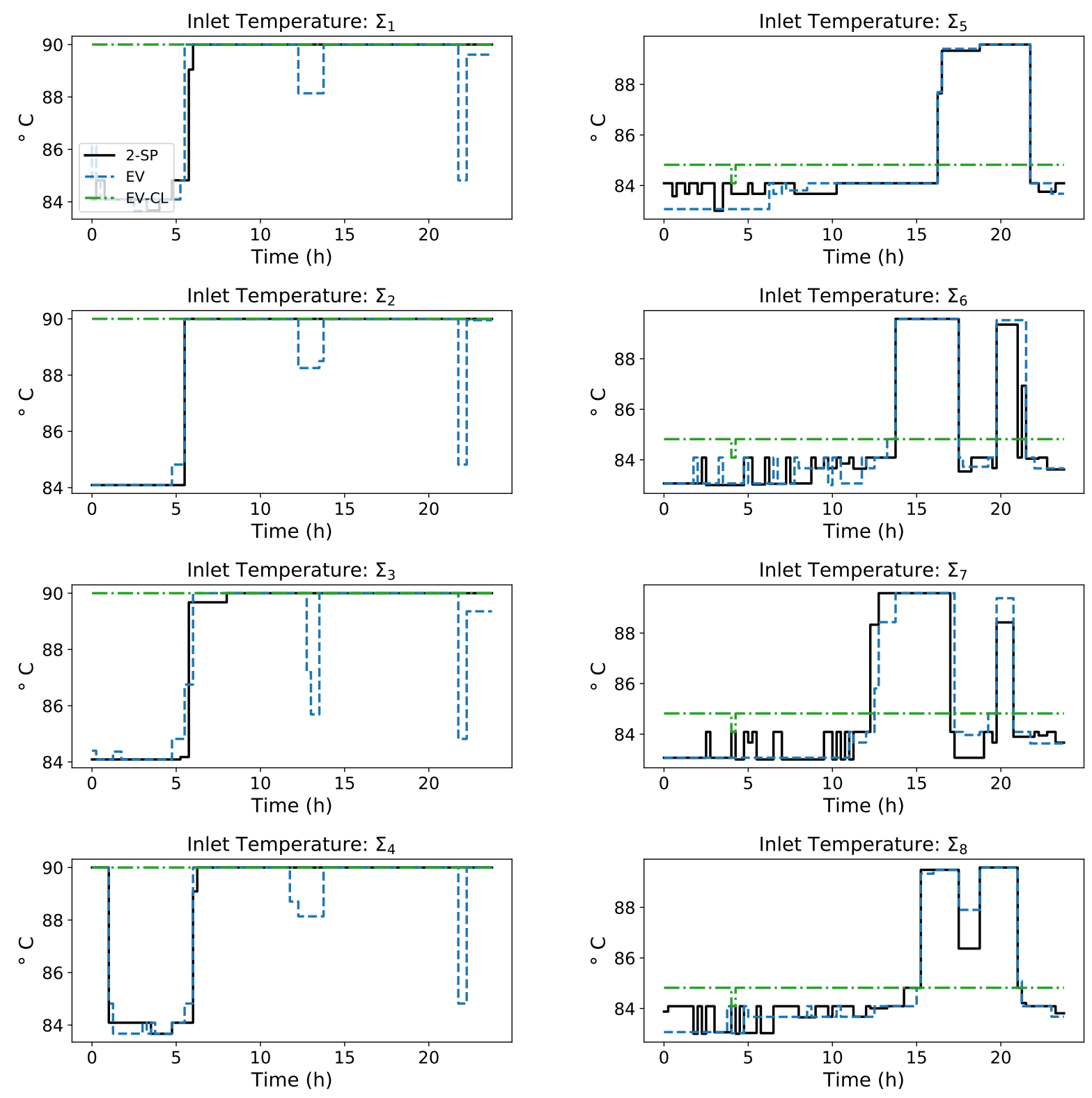

Figure S4: Stochastic programming case study results: inlet temperature per scenario (left column: low demand scenarios, right column: high demand scenarios) 

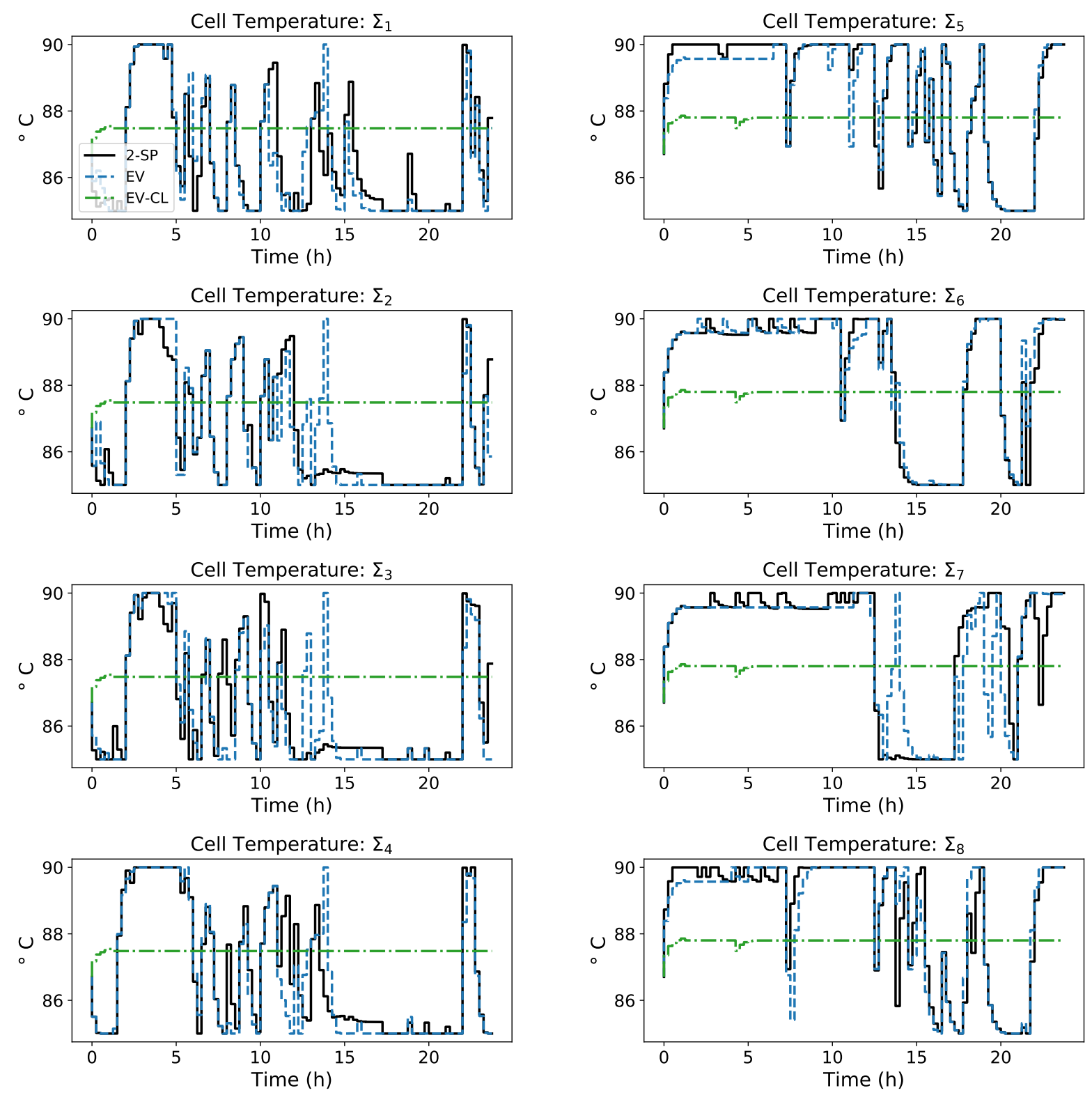

Figure S5: Stochastic programming case study results: cell temperature per scenario (left column: low demand scenarios, right column: high demand scenarios) 

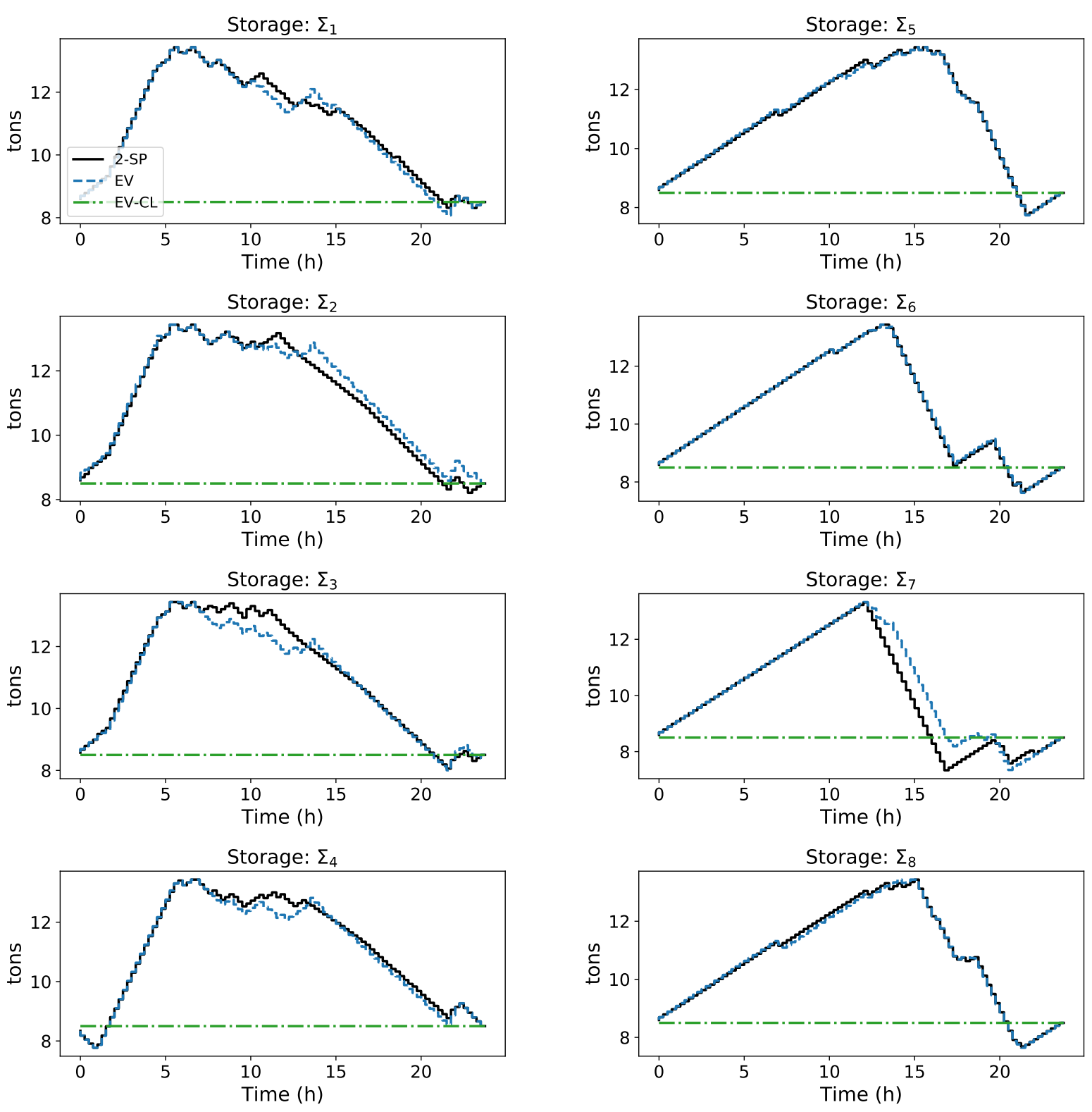

Figure S6: Stochastic programming case study results: storage level per scenario (left column: low demand scenarios, right column: high demand scenarios) 